\title{
Narrativas virtuales para la reconstrucción del Sujeto Ecológico de nuestro tiempo*
}

\author{
José Gutiérrez-Pérez
}

Universidad de Granada, Granada, España. Email: jguti@ugr.es

\begin{abstract}
Resumen: El artículo ofrece un análisis crítico del impacto contemporáneo que está teniendo la proliferación de una Educación Ambiental (EA) de nueva generación apoyada por herramientas tecnológicas virtuales en la construcción de una renovada identidad profesional, de un sujeto ecológico postmoderno en continua reconstrucción, reciclado por la influencia que ejerce la tecnología en su práctica laboral ordinaria y en su vida cotidiana como ciudadano ambientalmente comprometido. A los treinta años de Tbilisi se reconstruyen algunos patrones de cambio significativo valorando las limitaciones y oportunidades de los nuevos modelos. Desde los presupuestos de la investigación fenomenológica nos acercamos a los diferentes rasgos del nuevo sujeto ecológico de nuestro tiempo, donde un nuevo concepto de educador ambiental y de EA se perfila empujado por los avances tecnológicos al albur de realidades virtuales, redes sociales y medios de comunicación.
\end{abstract} biental

Palabras clave: Narrativas Virtuales, Sujeto Ecológico, Educación Am-

\section{Virtual narratives for the reconstruction of the Ecological Subject of our time}

\begin{abstract}
The article offers a critical analysis of the contemporary impact that is having the proliferation of an environmental education (EE) of new generation, supported by virtual technology tools, in the building of a renewed professional identity of an ecological postmodern subject in permanent reconstruction, recycled by the influence technology has in his normal working practice and in his daily life as citizen environmentally committed. Away thirty years from Tbilisi, some patterns of significant change are reconstructed, valuing the constraints and opportunities of the new models. From the phenomenological research budgets we approach the different features of the new ecological subject of our time, where a new concept of environmental educator and $\mathrm{EE}$ are outlined driven by technological advances at the risk of virtual reality, social networks and media.
\end{abstract} Education

Key words: Virtual narratives: Ecological Subject, Environmental

\section{Narrativas virtuais para a reconstrução do Sujeito Ecológico do nosso tempo}

Resumo: O artigo apresenta uma análise crítica do impacto contemporâneo é ter uma proliferação de educação ambiental (EA) da nova geração suportadas 
por ferramentas de tecnologia virtual para construir uma identidade renovada profissional de reciclagem ecológica pós-moderna por influência do tecnologia em sua prática normal de trabalho e na vida cotidiana como cidadãos ambientalmente comprometidos. Aos 30 anos de Tbilisi, foram reconstruídos alguns padrões de mudanças significativas, avaliando as limitações e oportunidades dos novos modelos. A partir dos orçamentos de pesquisa fenomenológica que nos aproximamos as diferentes características da nova auto ecológicas do nosso tempo, onde um novo conceito de educador ambiental e EA são descritas impulsionado pelos avanços tecnológicos com o risco de realidade virtual, redes sociais e mídia . biental

Palavras-chave: Narrativas Virtuais, Sujeito Ecológico, Educação Am-

“El hombre se está convirtiendo en un ser primitivo con mucha información” Julián Marías

\section{Introducción}

El texto subraya la perplejidad que está provocando el torbellino de avatares, innovaciones y cambios tecnológicos en las distintas generaciones de educadores ambientales y en la flexibilidad, capacidad de reconversión, reciclaje y mimetismo que han de adoptar los contextos de intervención que los envuelven, donde muchas prácticas profesionales continúan aún aferradas a modelos más presenciales "de Baja Definición Tecnológica”, que exigen en las cláusulas de su contrato de interacción el imperativo de la participación física del ciudadano para el desarrollo de los programas. Los dilemas que se plantean en el texto se refieren a cómo hacer compatibles estos nuevos mundos virtuales con las demandas de un sujeto ecológico no atemporal, de nueva generación, que sea capaz de integrar en los programas la contemporaneidad de los problemas reales desde los instrumentos y narrativas que ofrece la red, sacándole partido real y poniendo la alta definición tecnológica al servicio de la sostenibilidad con perspicacia e inteligencia, desde los nuevos cánones del ciberactivismo y los estándares de las nuevas narrativas no lineales construidas desde la pluralidad de medios.

Un especial énfasis se da al preguntarnos si la EA tiene algo que hacer y decir más allá del currículum clásico y neutral ante conflictos vitales y cruciales como el de la situación de crisis económica del mundo actual; las pandemias mundiales, las catástrofes asociadas a causas humanas y los modelos de civilización que nos envuelven y en qué medida los avances en las tecnologías de la información y la comunicación hacen más viables estos planteamientos favoreciendo la comprensión crítica y agilizando medidas de solución. A la vez, nos preguntamos si entre los fines de esta nueva modalidad de EA reconstruida hemos de incluir retos globales como 
la revisión de los modelos de organización económica, la evaluación de instrumentos del capitalismo que mantienen vivas las macroestructuras geopolíticas contemporáneas y los modos de organización social que favorecen a unos más que a otros.

También se discuten los obstáculos y resistencias que han de afrontar los educadores ambientales para atender estas demandas de la sociedad actual, cuyos requerimientos han de contribuir a armonizar los modelos tradicionales de la EA integrándolos desde la versatilidad y flexibilidad de los modernos instrumentos virtuales, pues es evidente que: facilitan interacciones complejas en tiempo real, favorecen los análisis multidireccionales y estimulan la explicación de fenómenos desde la pluralidad de fuentes, puntos de vista y enfoques complementarios.

Mediante una aproximación investigativa de corte fenomenológico (Gutiérrez, 2010) nos acercamos a las diferentes caras con que se muestra el sujeto ecológico de la sociedad de nuestro tiempo en redes sociales, medios de comunicación de masas, publicidad, productos de la ciencia, el arte y la cultura tales como literatura, cine,...; política, economía y marketing como un ideal de cambio envuelto en controversias y contradicciones propias de una sociedad postmoderna no exenta de paradojas en la que las multinacionales promueven discursos proambientales mientras esquilman los más recónditos rincones del planeta frente a construcciones idealistas de movimientos ecologistas que desde posiciones románticas y filantrópicas denuncian con agallas las atrocidades más impunes ante recursos, territorios, especies y espacios, marítimos y continentales.

Las dinámicas del conocimiento ambiental, llevan también asociados procesos no inocentes de visibilidad, accesibilidad y hegemonía conceptual dignos de ser considerados. Definir algunos criterios para una lectura histórico-electrónica del presente puede ser útil para fotografiar cómo se nos ve y cómo se pretende que se nos vea en estos nuevos medios de difusión de la información. Finalmente nos preguntamos en qué medida constituyen los educadores ambientales del siglo XXI un nuevo sujeto histórico susceptible de desplegar cambios históricos duraderos capaces de transformar el sistema social y ambiental de forma contundente en el sentido que le asigna Rodríguez (2006):

“el concepto de sujeto histórico hace referencia a una articulación históricamente determinada y constitutiva de sujetos sociales, políticos y culturales específicos que, en función del estado actual y futuro previsible del desarrollo del sistema de dominación imperante, logra poner bajo su articulación y en función del proyecto histórico que da sentido a su propia articulación, tanto a los sujetos con intereses y proyectos contrapuestos, como a las corrientes y tendencias espontáneas que resultan de la compleja combinación de proyectos y visiones de sentidos diversos... El sujeto histórico (ecológico), no es por eso un ente homogéneo, sino que está compuesto por la rica y compleja diversidad que genera la vida social y política, pero que 
confluyen temporal y parcialmente en un proyecto, en una plataforma, en un punto de acuerdos. Sus componentes por tanto, están condicionados por la dinámica de la propia realidad de la que forma parte cada actor y el sujeto histórico en su conjunto.”

\section{Educación Ambiental de Alta Definición y Bajo Voltaje: una aproximación fenomenológica}

Catalogada como una nueva modalidad de EA, la Educación Ambiental de Alta Definición (EA-AD) está servida y ha ocupado su propio espacio en el sector de lo ambiental. Caracterizada por un elevado nivel de sofisticación instrumental en los medios que la promueven; mediatizada por unas narrativas en “Tres D”, cargadas de simbolismo e interactividad virtual; exentas de presencialidad y propias de estos nuevos mundos virtuales a que nos arrastra la ciberactividad desenfrenada de la sociedad de la información y/o del conocimiento, una nueva modalidad de EA surge en la sociedad de nuestro tiempo y con ella un nuevo sujeto ecológico reconstruye su identidad profesional y ciudadana para atender las demandas del "tercer entorno", entendido como un nuevo escenario de interacción asociado a las nuevas tecnologías de la información de la comunicación y que "difiere profundamente de los entornos naturales y urbanos en los que tradicionalmente han vivido $y$ actuado los seres humanos" (Echevarría, 1999: 14) ${ }^{1}$.

Este texto evalúa las potencialidades y los retos que acarrean los nuevos escenarios, a la vez que, ejemplifica algunos riesgos como consecuencia de su sutil instrumentalización por parte de la mercadotecnia, la publicidad y la sociedad de consumo. Invita a repensar la magia de la comunicación no presencial y el poder de seducción de la accesibilidad sincrónica a un sin fin de imágenes, sonidos, documentos, datos y herramientas tecnológicas de distinta naturaleza hipertextual que hacen uso de lo ambiental como instrumentos de comunicación, denuncia, información, cooperación o mercadeo sin unos límites físicos en el espacio ni el tiempo que le impongan cortapisas.

A lo largo del documento se constata que la EA-AD está dotada de un elevado poder de penetración en la vida cotidiana, pero a su vez, lleva aparejado un "Bajo Voltaje” (BV) en su capacidad de transformación, perdurabilidad y capacidad de cambio real de las organizaciones, de los comportamientos, de las actitudes y de los estilos de vida de la ciudadanía contribuyendo a tejer una estructura identitaria superficial, muy informada y ampliamente comunicada, pero exenta de compromiso real y desprovista de capacidad de transformación y cambio de realidades.

Entre la vida y la muerte, la EA se bate hoy en un duelo que gira en torno al mundo de la alta definición y el espejo del bajo voltaje que nos devuelve como imagen la sociedad al analizar la rentabilidad de nuestro 
trabajo como educadores ambientales y la eficacia de nuestros programas. La llegada del santoral laico ambiental al calendario Zaragozano y la incorporación del discurso ecológico a las series televisivas de mayor audiencia e impacto internacional, tipo Simpson, definen bien este modelo de Alta Definición. La visibilidad mercantil frente a la vocación de cambio deja mucho que desear, también en los ritos y prácticas sociales que venimos profesando y que sin querer hemos adoptado en muchas ocasiones haciendo de ellas algo propio en un buen número de programas pseudoeducativos arrastrados por la simple inercia de discursos medioambientalistas atiborrados de mercadotecnia y asépticos al compromiso.

La Educación Ambiental de Alta Definición es aquella que penetra en los diferentes contextos de la vida cotidiana en forma de mensajes, programas y actividades, en diferentes formatos, con distintas manifestaciones, bajo estructuras y soportes variados, de la mano de los diferentes medios de comunicación, estrategias de marketing e instrumentos tecnológicos. Pero el que esté presente como discurso no significa que lleve aparejado un cambio real en los comportamientos, actitudes y estilos de vida de los ciudadanos. Por eso hablamos también de Bajo Voltaje, como una intensidad de corriente débil que apenas da para iluminar las lámparas de aquella ecoescuela cuya mayor aspiración reside en llegar a colgar su bandera verde en el tejado del edificio o en adornar la mesa del despacho del director con la insignia de "ambiental", sin que nadie se cuestione por el alcance de su programa, cuya energía debería de servir para alumbrar trayectorias de cambio duraderas en la comunidad, en cuanto programas de largo alcance, no meramente ocasionales ligadas a la celebración de una efeméride "a bombo y platillo".

Como en los circuitos eléctricos que aprendíamos en las clases de física, el voltaje está asociado a resistencias, y la pérdida de intensidad se debe a la resistencia de los canales que conducen la electricidad, a la distancia que hay entre la fuente y el destinatario, a las divergencias entre intereses y finalidades confrontadas, a las fugas de caudal que se producen desde el origen de la toma hasta el final del cauce, al balance que se establece entre los propósitos iniciales y el saldo negativo que arroja el lo logro precario de metas finales.

\section{Publicidad, Mass Media y Alta Definición}

La publicidad es uno de los instrumentos más sutiles de la alta definición, uno de los campos que más ha utilizado el eslogan ambiental y la identificación empática como estrategia de venta, a través de la asociación de personajes famosos e ídolos con el producto objeto de venta. El atractivo físico del top-model nos seduce e hipnotiza haciéndonos creer que consumir un determinado producto nos da cercanía y accesibilidad a ese personaje famoso. La evaluación de programas y campañas dirigidos al desarrollo de actitudes y comportamientos ambientales ha puesto en evidencia que 
las estrategias informativas son el recurso habitual y más caro, aunque no el más efectivo (Benayas et al. 2003).

La prensa verde ha ido creciendo y multiplicándose como otra manifestación más de la alta definición. Su enorme poder para olvidar o desenterrar historias es infinito, podemos comprobar los movimientos pendulares a los que venimos estando sometidos desde las coberturas mediáticas. También es sorprendente cómo hay cuestiones que con el paso del tiempo se van dejando a un lado; problemas que hoy parecerían insolubles, objeto de las más acuciantes alarmas vitales, pasan al limbo del periodismo dejando de ser noticia en sueño de los justos. Algunas cuestiones que en su día se consideraron inminentes catástrofes medioambientales parecen ahora como simples recuerdos de una época pasada. Ya sea porque el problema se ha solucionado, la opinión pública ha perdido interés o porque en realidad nunca hubo demasiado que temer, a veces las grandes preocupaciones simplemente se desvanecen. Esta es la foto en negativo, la otra lista de los problemas medioambientales olvidados (Foreign Policy, 2008) y muy recientemente suplantados por las modas del cambio global tales como: efecto invernadero, capa de ozono, transgénicos, desertización, energía, consumo...

La alta definición se manifiesta en fenómenos como la fama que otorgan determinados medios, como televisión, literatura, cine y empresa; y el uso del ambiente como anzuelo de su narrativa. Una selección de estos ámbitos nos la ofrecen los resultados de los trabajos de estos autores Ruiz \& Conde 2002, donde el mensaje ecológico está presente en todos los ámbitos de la esfera publicitaria, desde la alimentación a la belleza, la telefonía, el transporte y la empresa farmacéutica, el aseo personal, la cosmética, el mundo automovilístico, la literatura, el cine, el deporte y el ocio.

\section{Alta Definición e Investigación Ambiental}

Alta definición científica de los estudios, diseños de investigación sofisticadísimos para analizar la conducta ambiental de la ciudadanía; teorías complejas y patrones de cambio contrastado en el campo de la planificación estratégica, la psicología, la sociología y la ingeniería en la base de diseños de investigación predominantemente descriptivos e inmunes al cambio. Estudios, por lo general, dotados de muy baja definición en el campo educativo en cuanto a cómo atender estas cuestiones con profesionalidad, sin fundamentalismo y capacidad de mediación real en los conflictos; con bajo voltaje en potencial de transferencia de los hallazgos de las investigaciones a la realidad y poca capacidad de generalización de los modelos que funcionan en entornos reducidos para ser traducidos a aplicaciones innovadoras basadas en la evidencia y buenas prácticas extrapolables a contextos variados más amplios fuera del entorno escolar, ya sean rurales y urbanos, presenciales o virtuales. 


\section{Bajo Voltaje y Cambio Curricular}

El Bajo Voltaje se manifiesta también en el estrepitoso fracaso que ha acarreado la integración de temas transversales de contenido ambiental en las asignaturas clásicas del currículo escolar promovido desde los años 90 en España y exportado a otros contextos latinoamericanos (Lencastre, 2000; Reigota, 2000; GonzálezGaudiano, 2000) que más recientemente ha desembocado en una búsqueda esperanzadora hacia nuevas fórmulas, más creativas, que permitan conectar el currículo a los problemas reales. El caso de la educación para la ciudadanía en España es otro escándalo nacional que ejemplifica bien las múltiples resistencias que hacen que el potencial de corriente caiga y pierda intensidad, en este caso acaudillada por el sector más conservador del clero, como motor de objeción ante la educación para la ciudadanía.

Muy baja implicación de la EA en los procesos de participación relacionados con gestión del riesgo, democratización de decisiones ambientales, gobernanza... Esto ha dado lugar a serios fracasos en temas como la gestión municipal de los presupuestos ambientales, la instalación de centros de confinamiento de residuos peligrosos bajo los efectos del NYMBY ("not in my back yard", "no en mi patio trasero"), o la interferencia en situaciones de desarrollo y progreso de una determinada región: oponerse a la instalación de antenas, la construcción de una autovía o la instalación de una desalinizadora, la realización de un transvase, o la instalación de un huerto solar,... ejemplos de esta naturaleza nos sobran; cada cual posee su singularidad y requiere de estudios técnicos ecuánimes, combinados con voluntades ciudadanas y políticas de gestión transparente que permitan convertir en aprendizajes los errores de los procesos de toma de decisiones participada.

\section{Política Ambiental y Alta Definición}

De alta definición pueden catalogarse también las propuestas de un grupo de parlamentarios ingleses que proponen una nueva fórmula de mercadeo con el CO2, ya no entre países de primer y segundo mundo, sino entre empresas y ciudadanos, a través del canje de emisiones por ayuda social; mediante un carnet por puntos que permitiera sancionar a aquellos ciudadanos que sobrepasasen su cuota límite de emisiones establecida por su país de residencia. Si bien la iniciativa fue rechazada por el parlamento inglés, la idea viene a abundar en la gran brecha entre países, ya ampliamente aireada desde la compra-venta de emisiones norte-sur, y ahora trasladada al terreno de la vida cotidiana: un español medio emite en torno a 300 Toneladas de CO2, frente a la cuota de un habitante de Bangladesh, 300 kilos, o los 60 de uno de Mali. Pero incluso las estimaciones entre ciudadanos de un mismo país oscilan entre las 39 Toneladas anuales de un deportista de élite, las 12 de un ciu- 
dadano de clase media y las casi 3 de un ciudadano ambientalmente comprometido ${ }^{2}$. Entre las soluciones que aporta Rifkin (2002) al debate sobre las energías y las economías en su libro La economía del hidrógeno, sugiere que el cambio de tecnologías es la esperanza que le queda a la humanidad para salvar el planeta, y ese cambio no implica un retroceso, sino un avance en la exploración de nuevas tecnologías, en la creación de una biosfera menos contaminada (Blaschke, 2007, p. 157), y propone como alternativas energéticas:

"Reducir el consumo del combustible fósil en un 20\% como mínimo, para lo que es preciso introducir nuevas tecnologías en la industria.

Que los Gobiernos impongan límites al carbono y una reducción de emisiones de CO2 de un 30\% de aquí a 2020.

Que los países exploten energías renovables en forma de energía solar, eólica, hidrológica, geotérmica, biomasa o energía de las olas.

Que los países asuman un compromiso para realizar la transición a una era de hidrógeno, que es el elemento más ligero y abundante en el Universo y, por supuesto, menos contaminante.

Reconfigurar las redes eléctricas de cada país, para conseguir más eficiencia y rentabilidad en la distribución de la energía.”

\section{Bajo Voltaje y Economía Ecológica}

La crisis económica mundial desatada en 2008, deja en un segundo plano la preocupación febril que habían empezado a manifestar los mandatarios políticos por las cuestiones relacionadas con el cambio climático; entre otros, diez países de la Comunidad Económica Europea ya empiezan a manifestar en público que el cambio climático tendrá que esperar pues no consideran que éste sea el momento de fijar estrategias que sacrifiquen la expansión económica, y no están dispuestos a reducir emisiones ni a contener la expansión industrial en un momento de virulencia económica ${ }^{3}$. Todo el autobombo que proclamó la alemana Ángela Merkel cuando estaba de presidenta de turno de la Unión Europea, donde se comprometía a que para 2020 se rebajasen las emisiones de gases de efecto invernadero en un 20\% respecto a las tasas de 1990 , y a que el $20 \%$ de la energía total consumida en el espacio europeo, y en cada país miembro en particular, fuese de origen renovable. Un plan que a corto y mediano plazo requiere inversiones del orden de $180 \mathrm{mil}$ millones de euros y que presidente de turno (Nicolás Sarkozy en ese momento) debió retirar del debate público del parlamento europeo, ante la resistencia de Alemania, apoyada por Italia, Portugal, Polonia, 
Rumanía, Hungría,... Estas son las palabras de Berlusconi ante el asunto: "no estamos para hacer de quijotes cuando China o EEUU no cortan sus emisiones”. La coartada de la crisis económica ha llevado a algunos gobernantes a afirmar que no es momento para invertir en temas como el cambio climático, pues las exigencias económicas que conllevan estas medidas podrían agravar la crisis. Lo importante ahora, afirman bastantes mandatarios, es incentivar el consumo y reactivar el crecimiento económico. El medio ambiente siempre puede esperar. Esta miopía de la inmediatez cortoplacista ignora el origen de la crisis y sus vías de solución. La razón de la crisis reside precisamente en los estilos de vida de los países desarrollados y los modelos de organización económica basados en la búsqueda de beneficios inmediatos y en un consumo de recursos por encima de las posibilidades de explotación del planeta.

Si 2007 se ha consagrado en la historia como el año de la sostenibilidad por excelencia: Al Gore coronó el nobel por su acción mesiánica incomodando con los mensaje sobre el cambio climático y Leonardo di Caprio confesaba su emoción porque por una vez en la historia la entrega de Oscar en Hollywood se ajustaba a criterios de sostenibilidad al contratar Limusinas de motor híbrido, menús ecológicos y miles de bombillas de bajo consumo. 2008 se distingue por una presencia prometedora de defensores del ambiente entre sus primeras espadas: la Revista Foreign Policy viene seleccionando de un tiempo a esta parte los 100 intelectuales más influyentes ${ }^{4}$, cuyos pensamientos están moldeando el mundo, revolucionando la ciencia, transformando el arte y la literatura, o alimentando las filas de resistencia del pensamiento crítico y a contra corriente ante las inercias fenómenos de masas. La presencia de personalidades de reconocida imagen pública en el campo del ambiente supone una forma de legitimación de la preocupación por estas cuestiones. 2009 pasó a la historia porque el gigante de la animación, Disney, se sumó a la preocupación mundial por el medio ambiente y el cambio climático estrenando un canal de vocación ambientalista, Disneynature apelando al sentimiento ecológico de los espectadores a través de una serie de documentales, con el medio ambiente como coartada principal, comenzando con el estreno de Earth, que narra el viaje de tres madres - una osa polar, una elefante y una ballena jorobada - junto a sus vástagos, estuvo perfectamente sincronizado en 2009, con el "Día de la tierra".

Y 2010 nos sitúa justo en el ecuador de la década proclamada por Naciones Unidas como Década de la Educación para el Desarrollo Sostenible y en el punto de arranque de los Objetivos del Milenio, todo ello sin un horizonte empírico que acredite con independencia de criterio, la validez de las celebraciones y fiabilidad las cotas de progreso social y ambiental logradas realmente al margen de la retórica generada, el marketing desplegado y el eco con que se han instrumentado los multitudinarios encuentros realizados. 


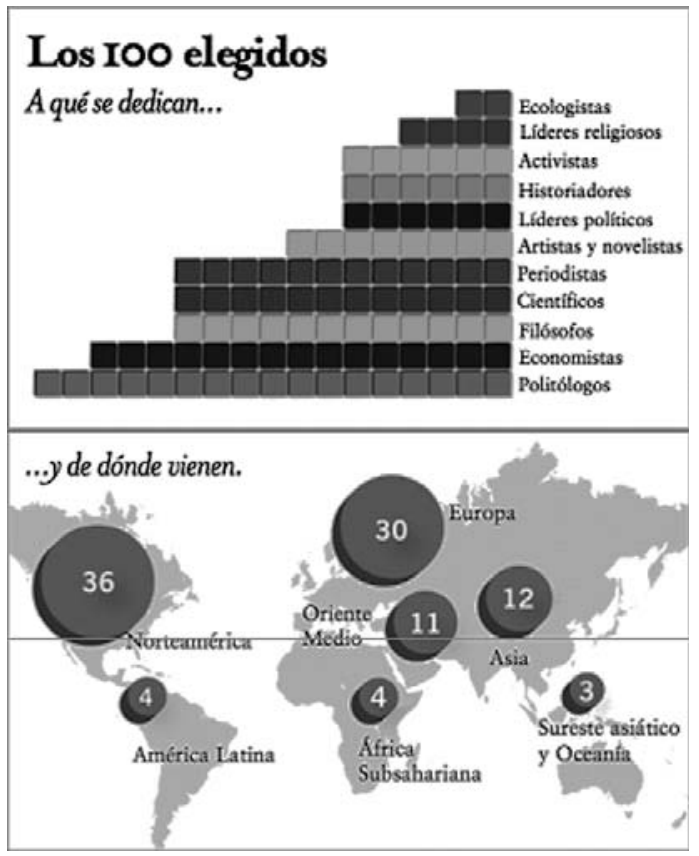

Pero cuando se profundiza en el asunto, descubrimos la no neutralidad de los mensajes del norte, incluso de los mensajes de autores de reconocida fama internacional en el campo ambiental por haber hecho aportaciones relevantes a lo largo del tiempo; el caso más emblemático es el de James Lovelock y sus últimas propuestas en defensa activa de la energía nuclear enmascaradas en el éxito alcanzado por su hipótesis Gaia y cómo ello ha contribuido a la venta de sus últimos libros:

"Necesitamos una cartera diversificada de fuentes de energía, entre las cuales la nuclear será predominante, al menos hasta que la fusión se convierta en una opción viable” (Lovelock, 2007:31).

\section{Ecofelicidad, Bienestar y Alta Definición}

La alta definición parece estar positivamente correlacionada con una cierta componente de distinción asociada a un sujeto ecológico que habita la sociedad del bienestar y disfruta de unas cotas básicas de confort, calidad de vida y desarrollo humano. Eco-Felicidad, Índices de Bienestar y Ranking de Felicidad son algunos de los slogans que durante los últimos años el Instituto para la Investigación Social, de la Universidad de Michigan, ha desarrollado. Se han aplicado más de 350.000 entrevistas para averiguar 
el nivel de felicidad de la gente a través de dos preguntas: "Teniendo en cuenta todos los factores de su vida, ¿diría que es muy feliz, bastante feliz, no muy feliz o infeliz?" y "¿en estos días, cual es el nivel de satisfacción en su vida?". Encabezando la lista de los países más felices se encuentra Dinamarca, seguida por Puerto Rico y Colombia. En cambio, la población de Zimbabwe es la más infeliz del planeta. Tampoco están satisfechos los habitantes de Moldavia y Armenia, los siguientes por la cola. Estados Unidos aparece en el número 16, detrás de Nueva Zelanda, y Portugal está justo por detrás de Italia, puestos 46 y 45 respectivamente. Los habitantes de los países más ricos suelen estar más satisfechos, pero el dinero no lo es todo. Es más importante la libertad para poder tomar decisiones. La democracia y la tolerancia social son los dos factores más decisivos en la satisfacción de la población para el politólogo Ronald Inglehart, director del estudio y autor principal del ensayo publicado en la revista Perspectives on Psycological Science (2008). Como muestra señala la tolerancia social y el sistema democrático de Dinamarca, Islandia, Suiza, Holanda y Canadá, que se sitúan entre los 10 primeros de la tabla.

"La forma de maximizar la felicidad parece cambiar con el incremento del desarrollo económico. En sociedades muy básicas, la satisfacción está estrechamente ligada a la solidaridad grupal, la religiosidad y el orgullo nacional. En niveles más altos, la libertad de elegir es la capacidad que tiene un mayor impacto", señala Inglehart, quien también ha destacado el incremento de satisfacción entre las repúblicas ex socialistas. "Mientras que la mayor parte de los países ex comunistas muestran niveles muy bajos de felicidad, muchos de ellos muestran incrementos muy amplios en bienestar. El colapso del comunismo ha sido seguido, en general, por un gran declive en el estado del bienestar que ha vuelto a subir con el crecimiento económico".

Si bien es cierto que el progreso científico-técnico ha desterrado muchas fuentes de incertidumbre (especialmente en el campo de la salud y la medicina) no es menos cierto que allí donde más se ha progresado han surgido nuevas fuentes de incertidumbre inéditas, más letales y persistentes a largo plazo, trabadas con el factor humano, el riesgo y las insaciables ansias de bienestar y felicidad, pero, "los miedos modernos pueden calificarse de paradójicos: cunden precisamente allí donde el progreso más éxitos ha conseguido, allí donde las causas del miedo antiguo (a los elementos naturales) han sido si no derrotadas, sí muy aliviadas. La hipocondría es el más visible de los nuevos miedos: mientras la medicina no cesa de cosechar triunfos, aumenta extraordinariamente el pavor a enfermar. De igual modo que a mayor proteccionismo y beneficencia estatal, mayor fragilidad ciudadana: el ciudadano occidental es, en teoría, el más libre, el más protegido, el que cuenta con más recursos y apoyos para enfrentarse a las dificultades cotidianas, pero es el que más problemas cree tener, el más infantilizado y llorón, el más frágil” (Puigverd, 2008).

Carlos Fuentes (2008), en “La voluntad y la fortuna” argumenta a este respecto: 
“-Hay que medir el placer, la felicidad, el gusto de la gente. Tú que eres tan culto... ¿ ¿crees que existe una ciencia de la felicidad? ¿Cuánta felicidad necesita el ciudadano medio? ¿Mucha, poca, nada?

...hay que hacerles creer a los jodidos que aunque estén jodidos son más felices que tú y yo.

Mira nada más los gringos. ¡Qué cara les resulta la prosperidad! Trabajan sin descanso, comen mal,...no tienen vacaciones, no tienen seguro social, se retiran a los cincuenta años y se mueren a la vera de una cortadora de pasto. Mucho trabajo, mucho dinero y poca satisfacción... ¡Vaya felicidad!”

\section{Sujetos ecológicos en tránsito permanente y ciclos de vida profesional en constante evolución}

La Educación Ambiental no es ajena al devenir histórico. A lo largo de las tres últimas décadas la EA ha sufrido procesos de cambio interno de distinta naturaleza que han afectado a sus fines, metodologías y formas de conceptualización, fruto de la evolución del campo disciplinar y de las presiones externas. Esto ha acarreado importantes cambios en el rol desempeñado por el sector de los educadores ambientales y la progresiva metamorfosis sufrida como consecuencia de su institucionalización. Como argumenta Foucault (1972:202): "los discursos se desarrollan en la dimensión de una historia general; son reflejo de las instituciones, de los procesos económicos y de las relaciones sociales,... revelan el nivel singular en que la historia da lugar a tipos definidos de discurso, que tienen sus propios tipos de historicidad, y que están relacionados con todo un conjunto de relatos y narraciones".

Desde sus orígenes, cada etapa histórica y sus avatares han influenciado sus argumentos y condicionado sus discursos. Desde esta consideración, una mirada global a las tres décadas que siguen a la proclamación del eslogan "Tbilisi" ha de permitirnos revisar el pasado y redireccionar el futuro. Pero para ello no podemos mirar solamente los textos generados (pecaríamos nuevamente de hacer la historia de los grandes reyes, olvidando al pueblo como sujeto histórico), debemos contextualizar los acontecimientos y desenmascarar relaciones múltiples entre microhistorias locales y bucles de información múltiple. El avance del discurso educativo-ambiental ha estado condicionado por las preocupaciones del contexto histórico, y su devenir como campo de reflexión ha sufrido los vaivenes de la postmodernidad, las crisis de fundamento del método científico derivado del positivismo llevadas al campo socio-educativo y la competencia por las hegemonías del lenguaje en términos de conquista profesional y visibilidad lingüística (el caso del manido concepto “desarrollo sostenible” ilustra bastante bien este fenómeno).

La EA se ha consolidado como un campo muy permeable a las influencias del exterior, a los debates ambientalistas, a las reivindicaciones 
ecologistas, a las acciones de los políticos, a las teorías del aprendizaje, a las convulsiones de las Ciencias Sociales, a las discusiones sobre el desarrollo sostenible y sus vocablos derivados. En poco tiempo, la EA se ha convertido en un campo fértil, dinámico, plural, abierto, a veces desordenado e incluso confuso y sujeto a contradicciones fruto de la mezcolanza de teorías, fundamentos, metodologías, epistemologías y aportes profesionales de diferentes áreas disciplinares y campos de conocimiento.

Siguiendo las propuestas sugerentes de Isabel De Moura (2006: 137) “es posible tomar la EA como un manojo de historias narradas por educadores ambientales en las que esa narrativa se compone de diversos eventos ambientales, presentándose fundamentalmente como una historia nativa que raramente ha sido objeto de investigadores externos al campo ambiental. Esa historia contada y recontada, sea en las introducciones o bien como tema central de muchas publicaciones ambientales, posee una historia que de manera recursiva orienta y sitúa a los educadores dentro de una trama común”, en un marco conceptual condicionado por un contexto y un arsenal de intereses alineados o contrapuestos: "Se trata de una operación que se produce a partir del entrecruzamiento del presente y el pasado, a través de una memoria selectiva que organiza una cronología de obras, autores y eventos como referencias histórico-temporales, proyectando como reinterpretación del pasado, un mirar ambiental que tiende a naturalizarse”

No podemos afirmar que el sujeto histórico-ecológico, sea un ente homogéneo, más bien está compuesto por la rica y compleja diversidad de interacciones y representaciones idealizadas que genera la vida social y política, cuyas coordenadas confluyen temporal y parcialmente en proyectos de mundos, en cosmovisiones alineadas o contradictorias que van cambiando a lo largo del tiempo. Es en este contexto donde la EA "representa al mismo tiempo una crítica y una alternativa a los procesos pedagógicos conservadores. Pero su crítica/alternativa no se limita al espacio educativo. Éstas se amplían al modelo económico, social y cultural vigente, así como a las formas de hacer política, ciencia y arte, sin olvidar que ella pretende influir en lo cotidiano, proponiendo relaciones sociales y afectivas basadas en la ética, en la justicia y en la sustentabilidad (Reigota, 1998: 23)

Teóricamente, la definición del sujeto histórico-ecológico solo es posible en función del cambio social, es decir, del cambio de las estructuras de dominación. En el contexto del actual estadio de desarrollo de la sociedad contemporánea, el sujeto historico se define y se moviliza social y políticamente, en función de su postura cultural, política e ideológica contraria al sistema capitalista de dominación y en cuanto actor protagonista del cambio social y portador de un proyecto de transformaciones que apunta hacia una nueva sociedad (Rodríguez, 2006).

En síntesis, el sujeto histórico es aquel campo de fuerzas y de movimientos organizados que apuntan hacia el cambio social. Por eso, la noción de identidad narrativa muestra su riqueza en el hecho de aplicarse tanto a la comunidad como al individuo. Podemos hablar de la identidad de una co- 
munidad como acabamos de hablar de un sujeto individual: individuo y comunidad constituyen su identidad al recibir estas narrativas que se convierten para uno y otra en su historia efectiva. Hay, por lo tanto, en la definición del sujeto histórico-ecológico actual, tres dimensiones interrelacionadas entre sí, a saber (Idem, 2006):

“a) que se sitúa en el campo político-ideológico y social contrario y alternativo al sistema capitalista de dominación;

b) que es portador de un propósito estratégico de cambio social; y

c) que es portador de un proyecto de nueva sociedad en la que lo ambiental se confunde con lo económico, lo social y lo biológico.”

Afirma De Moura (2006: 22) que "la idea de la invención del sujeto ecológico quiere destacar que, entre la búsqueda de verosimilitud en los auto-relatos y la creación deliberada de la narrativa literaria hay más continuidades de las que supone una nítida demarcación de los territorios de lo real y la ficción. Así, los relatos sobre la trayectoria profesional de los sujetos vinculados al ambiente se alejan de una historia natural, como sucede en la narrativa de ficción. Guardadas las diferencias entre los dos campos narrativos, las biografías narradas a través de trayectorias de vida también pueden ser vistas como espacios de ficción, a partir de los cuales, recordar y contar es siempre reorganizar y reconstruir una identidad narrativa. Esa auto-invención, a su vez trae consigo la invención del otro, de las relaciones de alteridad y, por tanto, de la identidad narrativa de un campo intersubjetivo y cultural en cuestión. De esta manera, la auto-invención de los sujetos es, simultáneamente, posicionada en un campo social y demarcadora de este mismo campo”.

En estas tensiones narrativas entre la ficción y la realidad se sitúan las narraciones del pasado ligadas a representaciones del románticas, inocentes y filantrópicas del colectivo ambiental; pero también se abren hueco los nuevos formatos que adquiere el sujeto ecológico del presente en los medios virtuales y redes de comunicación social de los mundos no vividos, simulados o creados artificialmente.

\section{Inocencia, romanticismo y filantropía: Tres rasgos endémicos del genotipo del sujeto ecológico del pasado}

La educación ambiental -creada por cambiadores de mundos, perfilada en conferencias de la Unesco y el PNUMA por educadores y ecologistas en la época de la guerra fría, publicitada por Naciones Unidas tras los acuerdos logrados entre los dos bloques en unos momentos difíciles- produjo unos textos de consenso que han sido, al menos de nombre, inspiradores de miles de actividades y programas en todo el mundo. Pero no los suficien- 
tes, o no suficientemente enfocados, o demasiado aislados de los restantes instrumentos de la política, la legislación, la fiscalidad, etc. Las razones de este relativo fracaso pueden estar tanto en la dificultad de integrar unas teorías contrarias a los actuales modelos de producción como en su propio desarrollo. Surgida como una corriente romántica, se esperaba que la educación por sí misma pudiera cambiar la sociedad. Ésta es la historia de los espejismos de la educación ambiental y ése, el primero (Calvo y Gutiérrez, 2007a).

La educación, reflejo de la sociedad de la que forma parte, no puede cambiar las estructuras sociales ni el predominio que ejerce la economía de mercado en las decisiones políticas, en el uso del territorio y los recursos, en la profundización democrática y la justicia de distribuir los recursos con equidad, “de la noche a la mañana”. De esto es de lo que estamos hablando cuando nos referimos a los problemas ambientales y al análisis de sus causas. Los profesionales de la educación ambiental han sido, y son, actores y constructores de su trabajo, un colectivo variado y comprometido, con diferentes formaciones y distintos ámbitos de desarrollo profesional: administraciones de gestión, docentes, ong, empresas, etc. Ha sido un largo construir a contracorriente, un camino solitario, demasiado solitario que por un lado ha impedido que los éxitos tuvieran visibilidad; por otro lado, los mundos de referencia eran los propios colectivos de educadores ambientales, produciendo submundos y comunidades de prácticas herméticas, con sus propios valores, cerrando círculos. Esto quizá fuera necesario en los primeros momentos, pero desde luego está fuera de lugar si se quiere que la profesión ocupe un espacio entre los instrumentos necesarios para lograr la preservación e iniciar el camino hacia la sostenibilidad. Hay que trabajar en las mismas arenas en las que se mueven los restantes actores y agentes, establecer escenarios de trabajo conjunto con los demás gestores, con los docentes o los agentes sociales, construir redes mixtas, mezclando los saberes en la construcción de escenarios donde el aprendizaje sea posible, involucrando partes interesadas (Calvo y Gutiérrez, 2007b). Por eso el educador ambiental de hoy no puede dar la espalda a los instrumentos de comunicación virtual como instrumentos de trabajo profesional derivados de una nueva cultura donde la interacción física y el intercambio presencial no forma parte exclusiva de uno de los mundos posibles en los que se mueve este nuevo sujeto histórico; muy a pesar de las voces críticas que ponen en tela de juicio la inutilidad de lo virtual ante los aprendizajes emocionales con se revela el contacto directo con el medio natural.

Por todo ello, reconocemos con De Moura (2006: 23) que lo que está siendo inventado en el acto narrativo autobiográfico de los educadores ambientales es, más allá de la dimensión personal de las vidas narradas, un sujeto ecológico que, idealmente, supone un actuar según una ética ambiental. La identidad narrativa, como una clave de sentidos de lo ambiental y abordada a partir de los autorrelatos de los educadores ambientales, se instaura en este caso, como horizonte de posibilidades del sujeto ecológico, comprometido en llevar adelante y extender los mejores ideales por el campo ambiental. De esta forma, al considerar las confluencias entre el campo y 
las trayectorias, buscaremos discutir las condiciones de producción y la configuración de los sentidos de lo ambiental, bien como inscripción particular en la emergencia de una identidad narrativa -experiencia que remite a una práctica social y a un perfil profesional particular: el educador ambiental-. En la búsqueda comprensiva de ese universo de sentidos confrontados entre identidad narrativa y cuestiones ético-políticas.

Tres rasgos endémicos destacamos en este intento de demarcación identitaria del genotipo del sujeto histórico-ecológico de un pasado reciente: romanticismo, inocencia y filantropía.

\section{Romanticismo}

Por la transparencia, ilusión e ingenuidad con que miramos el mundo los educadores ambientales, como herederos directos del utopismo y las ilusiones del ecologismo.

Por la nitidez de nuestras metas y la honestidad de nuestras acciones y proyectos para con la sociedad.

Como colectivo peculiar, con unas señas de identidad propias: en nuestras formas de pensar y hacer, de entender y afrontar las relaciones con el entorno, falta de ambición, exceso de altruismo, y técnicas muy peculiares para responder las demandas sociales.

\section{Inocencia}

Porque nuestra mirada no encierra segundas intenciones, ni aspiraciones de lucro.

Porque confiamos en que la educación además de encerrar un tesoro posee la formula sagrada del cambio social y la transformación de las conciencias colectivas.

Porque mientras ejercemos de predicadores atemporales inspirados en el humanismo roussoniano, la realidad se nos escapa a la velocidad de la luz hacia opciones más materialistas e impregnadas de practicidad.

Porque el propio mercado se come nuestro terreno e imita nuestras prácticas con mayor eficacia y rentabilidad en forma de Parques Temáticos Ambientalizados, Vacaciones Certificadas en la naturaleza y safaris familiares en ecosistemas exóticos.

\section{Filantropía}

Como sector, vivimos enquistados en las promesas del pensamiento filantrópico e iluminista con que mirábamos las flores del paraíso de hace ya más de un siglo. 
Los modelos que empleamos están basados en una formación ambiental cegada por los entornos escolares. Y eso se ha hecho extensivo a otros contextos, acarreando: reduccionismos metodológicos, ideológicos, epistemológicos y disciplinares

La educación ambiental no es una tarea inocente exenta de intencionalidades y propósitos, exige compromisos tangibles en la ciudadanía.

$\mathrm{Ni}$ se trata de enseñarle a los pequeños persistentemente lo mal que está el mundo ni tampoco de engañarles ocultando la realidad.

Debemos desvelar los secretos del entorno y hacerlos visibles a la población y a los destinatarios de nuestras acciones; por eso no podemos ser neutrales.

Con distintos matices según las tipologías de programas, "es así como se busca la comprensión de las relaciones recursivas entre campo social y trayectorias de vida, tomando la condición narrativa de esas interacciones como referente teórico y el análisis de las trayectorias como camino metodológico. En esas interacciones se constituyen mutuamente un campo ambiental, un sujeto ideal ecológico, y también las trayectorias profesionales y personales de los educadores ambientales, entendidas como una expresión de aquel sujeto ideal; abordadas como una identidad narrativa que perfila un sujeto ecológico, proyecto identitario abierto, apoyado en una matriz de trazos y tendencias supuestamente capaces de traducir los ideales del campo; los mitos, los ritos y las vías de acceso a la formación del educador ambiental; el recorrido de la EA como un conjunto de prácticas educativas que buscan legitimidad dentro del campo ambiental y educativo y, finalmente, las tensiones de la acción política en el campo ambiental, tratadas a partir de un doble movimiento: los tránsitos políticos de los sujetos ecológicos y las transformaciones de la esfera pública en la contemporaneidad que caracterizan una política en tránsito” (De Moura, 2006: 23).

\section{Narrativas virtuales y nuevos rasgos en el fenotipo de un sujeto ecológico reconstruido}

Con los entornos virtuales, los hipertextos e hipermedia, las narrativas visuales, y los modernos instrumentos de las redes sociales que brindan las nuevas tecnologías se desdibuja la linealidad clásica con que se han venido construyendo los relatos ambientales del pasado y aparece una nueva dimensión dialógica de la realidad, sometida a un cambio pensado de forma colectiva, en tiempo real, sin límites geográficos ni disciplinares para la interacción, exentos de jerarquías e inspirados en nuevas fuentes de autoridad y legitimación.

Las nuevas posibilidades de la meganarración auspiciada por tecnologías que incorporan artefactos y sistemas de comunicación en tiempo 
real, integradas en redes sociales activas que hacen posible añadir a nuestro arsenal de informaciones las historias electrónicas y comentarios almacenados en el entorno que nos rodea. Este es, quizás uno de los cambios más significativos que nos ha asaltado al sector de la EA desde que iniciamos nuestra singular andadura en 1997 en Tbilisi. Otro factor, no menos trascendente se recoge en este escrito, cual es el envite que ha sufrido el sector de la EA en paralelo a su legitimación identitaria al entrar en competencia abierta con las múltiples etiquetas adjetivadas de la sostenibilidad heredadas de la Cumbre de Río 92, consideradas más un lastre que una oportunidad de desarrollo sostenible real del colectivo.

La Eco-esfera, Eco-blogsfera y Eco-SecondLife nos permiten en la sociedad de la información alquilar varias películas de contenido verde para el fin de semana, blogear para actualizar nuestros ficheros verdes y programar itinerarios virtuales en las diferentes convocatorias otoñales, así como buscar empleos verdes y programar en nuestro simulador de vida una vivienda energéticamente sostenible, un eco-jardín con plantas autóctonas, una eco-mascota que contribuya a la conservación de las especies en el entorno local y una empresa no contaminante inspirada en la filosofía de la antideslocalización ${ }^{5}$. Algunos portales de redes sociales de ocio compartido y empresas de búsqueda de pareja incorporan ya la variable ecológica como un elemento determinante que adorna los perfiles de usuarios de estas nuevas vías de socialización humana.

También la institucionalización de las efemérides parece suponer un factor de modernidad, visibilidad y alta definición, pues al ponerle nombre a las cosas nos quedamos tranquilos, mientras las hipersuperficies hacen su agosto incitando al consumo desmesurado bajo pretextos de lo más sofisticados que engatusan al ciudadano haciéndole creer solidario y cómplice de obras de ecobeneficiencia, consumo solidario y ecológica sin cuestionarse lo más mínimo la trastienda de los protocolos de acción a que nos someten. Y nos podemos ver celebrando el día del árbol en un formato de efervescencia emocional similar al desplegado para la onomástica del día del padre, Halloween o San Valentín al compás de la melodía que nos marcan las tiendas de marca y sus interlocutores de competencia por los mercados. El llamado “efecto rebote” (Sorrel, 2007, Herring, 2008, Heras, 2009) ilustra muy bien las consecuencias de este tipo de actuaciones sentimentaloides en las que al remitir una postal electrónica de contenido ecológico, comprar vino ecológico o plantar unas encinas en un acto fraternal con la comunidad de vecinos tranquiliza nuestras conciencias y a veces consigue efectos contrarios a los deseados, pues se nos olvida luego que hay que echarles agua para que no se sequen.

La mayoría de estas celebraciones han sido designadas por la ONU, la Unión Europea y otros organismos de rango internacional: días, semanas, meses, años, lustros y hasta décadas (la UNESCO ha apelado recientemente por el Decenio de la EA para el Desarrollo Sostenible) han ido ocupando el laico santoral bajo el pretexto de que con hacer mucho ruido se incrementa la visibilidad, sin que ello lleve a promover cambios reales en 
los comportamientos o acciones duraderas de conservación en el territorio: “¿qué puede hacer la gente con tantas celebraciones internacionales?; si pensamos en los hombres y mujeres de buena voluntad, en los militantes de todas las causas justas, ¿ esperamos acaso que se entreguen como voluntarios 10 veces al mes?... De un ciudadano consciente que apoya el desarrollo y el cambio social en nuestro pobre y maltrecho mundo, ¿esperamos que se cuelgue en el pecho todas esas cintas de colores como las medallas de un general?, ¿o que vista cien camisetas con nobles mensajes?, ¿'somos sólo una sociedad de consumidores, de súbditos, o queremos ser actores sociales para producir este cambio imprescindible?” (El País, 2008) Según Greenpeace, administraciones y empresas usan este tipo de estrategias conmemorativas para lavar su imagen y justificar un activismo superficial que al embellecer las formas ignora los fondos, pero sin ocasionar cambios reales a corto, medio ni largo alcance. Todos sabemos que los días de (árbol, agua, aire, tierra, sin coche,...) tienen un impacto muy limitado, todo lo que acaba siendo muy frecuente y nos viene de fuera acaba por perder impacto como novedad y termina devaluando sus propios fines (Idem). Podemos dormir tranquilos celebrando efemérides ambientales en los más de cien días D, F, G ó H, y finalmente llegaremos a habituarnos a su celebración mercantilizada al compás del día de los enamorados, el día de la madre, el padre y la abuela; sin que nuestras conciencias se conmuevan más allá del coste del regalito ignorando los pingües beneficios comerciales de sus promotores. Programas endulzados de participación para maquillar conciencias sin cuestionar la raíz genética ni el fondo de los problemas ambientales (Calvo y Gutiérrez, 2007) como si la "cara no fuese el espejo del alma" cuyos rasgos más visibles se muestran en el fenotipo superficial de un sujeto ecológico atropellado por el marketing, la sociedad de consumo y las identidades mutantes que aporta el tercer sector a la comunicación no presencial y al compromiso simulado en Facebook, Tuenti, Twitter, Skup, Linkedin, Myspace, Hi5... 


\section{Notas}

* Este documento forma parte del Proyecto de Investigación EDU2008-03898/EDU, financiado por el Ministerio de Ciencia e Innovación de España. Un avance preliminar fue presentado en el Foro Nacional Mexicano de Educación Ambiental, celebrado en 2008 en Guanajuato (México).

${ }^{1}$ El primer entorno (e1) sería aquel que gira alrededor del ambiente natural al ser humano: el cuerpo humano, el clan, la familia, la tribu, las costumbres, los ritos, las técnicas de producción, la lengua, la propiedad... serían algunas de las formas humanas y sociales características del primer entorno (Ibidem: 28). El segundo entorno (e2) sería aquel que gira alrededor del ambiente social de la ciudad y del pueblo, es un entorno urbano, es un entorno social y cultural. Los espacios urbanos han desarrollado diversas formas sociales constitutivas de las maneras del segundo entorno: el vestido, el mercado, el taller, le empresa, la industria, la cuidad , el estado, la nación, el poder, la iglesia, la economía ... y donde la sociedad industrial sería su forma más desarrollada (Ibidem: 42). El tercer entorno es un nuevo espacio social en construcción, básicamente artificial y posibilitado por una serie de tecnologías que modifican las relaciones sociales y culturales que se dan y daban en los entornos primero y segundo (Ibidem: 14).

${ }^{2}$ Cálculos a partir de consultas en Carbon Footprint, Cero CO2, WWWF/ADENA y Greenpeace.

${ }^{3}$ Rituerto, R. (2008). Diez países de la comunidad económica europea piden que se aplace la lucha contra el cambio climático. Los gobiernos arguyen que no hay fondos para este objetivo. El País, 16 de octubre.

${ }^{4}$ Esta selección incluye desde algunos de los filósofos más reflexivos hasta clérigos que levantan masas: unos escriben mordaces historias de ficción y descubren los misterios de la mente humana; otros están en la vanguardia de las finanzas, la política y los derechos humanos. La lista de los 100 intelectuales públicos más influyentes ayuda a entender el embrión de algunas de las ideas más críticas que nacen en la sociedad contemporánea. Los hombres y mujeres de esta lista son algunos de los más sofisticados pensadores más influyentes de nuestra época. El criterio empleado para hacer esta selección no podría ser más simple: los candidatos deben estar vivos y todavía activos en la vida pública. Tienen que haber destacado en sus respectivos campos de estudio y ser capaces de influir en el debate internacional. Foreign Policy, abril-mayo, 2008

\footnotetext{
${ }^{5}$ Entendemos por antideslocalización aquellos modelos de organización empresarial que promueven la sostenibilidad en todas las facetas de la empresa desde el tratamiento de los residuos, los modelos de contratación del personal, al uso de productos procedentes del entorno local como base principal de la producción. Una empresa orientada desde la filosofía de la deslocalización ha de contribuir al progreso, equidad y desarrollo inteligente del territorio en que está enclavada y ajustarse a unos principios éticos de responsabilidad social corporativa en el uso de los beneficios.
} 


\section{Bibliografía}

Benayas, J., Gutiérrez, J \& Hernández, N. (2003), La investigación en educación ambiental en España, Madrid, Ministerio de Medio Ambiente. Calvo, S. y Gutiérrez, J. (2007a), El espejismo de la educación ambiental, Madrid, Morata.

Calvo, S. y Gutiérrez, J. (2007b), “Educación Ambiental de nueva generación: ¿programas para maquillar conciencias o herramientas participativas de cambio social?”, Cuadernos de Pedagogía 373, pp. 80-83.

De Moura, IC (2006), La invención ecológica. Narraciones y trayectorias de la educación ambiental en Brasil, Puebla, Universidad Iberoamericana-Lupus Inquisitor.

Echevarría, J. (1999), Los señores del aire. Telépolis y el Tercer Entorno, Barcelona, Destino.

El País (2008), “Ecoefemérides”, Periódico el País, junio.

Foucault, M. (1972), La arqueología del saber, México, DF., Siglo XXI.

Foreign Policy (2008), "Problemas medioambientales olvidados”, Foreign Policy, junio-julio.

Fuentes, C. (2008), La voluntad y la fortuna, México, DF, Anagrama.

González-Gaudiano, E. (2000), "Los desafíos de la transversalidad en el currículum de la educación básica en México”, Revista Tópicos en Educación Ambiental, volumen 2 número 6, pp. 63 - 69.

Gutiérrez Pérez, J. (1995), La educación ambiental: fundamentos teóricos, propuestas de transversalidad y orientaciones extracurriculares, Madrid, La Muralla.

Gutiérrez, J. y Pozo, $M^{a}$ T. (2005), "Stultifera Navis: institutional tensions, conceptual chaos, and profesional uncertainty at the beginning of the Decade of Education for Sustainable Development”, Policy Futures in Education 3 (3), pp. 296-308.

Ídem (2010), "Pluralismo metodológico y sostenibilidad: metanálisis contemporáneo de la investigación socioambiental”, Revista Sustentabilidad (es) 1 (3), pp. 1-17 [http://sustentabilidades.siderpco.org/ revista/ publicacion-03/pluralismo-metodologico-y-sostenibilidad-metanalisiscontemporaneo-de-la-investigacion-socioambiental]

Herring, H. (2008), "Rebound effect". In: Encyclopedia of Earth. Eds. Cutler J. Cleveland (Washington, D.C.: Environmental Information Coalition, National Council for Science and the Environment). [http:// 
www.eoearth.org/article/Rebound_effect> ]

Heras, F. (2009), “Os efectos rebote e outros efectos secundarios dos programas para mitigar o cambio climático: una mirada desde a educación e a comunicación”, Ambientalmente Sustentable 7, pp. 101-114.

Inglehart, R. (2008), “Development, Freedom, and Rising Happiness: A Global Perspective” (1981-2007) Perspectives on Psychological Science 3 (4), pp. $264-285$.

Lencastre, M.P.A. (2000), “Transversalización curricular y sustentabilidad: contribución para la teoría y práctica de la formación de maestros”, Tópicos en Educación Ambiental, volumen 2 número 6, pp. 07 - 18.

Lovelock, J. (2008), La venganza de la tierra. La Teoría de Gaia y el futuro de la humanidad, Barcelona, Planeta-Bloket.

Meira, P. (2009), “Outra lectura da historia da Educacion Ambiental e algún apuntamento sobre a crise do presente”, Ambientalmente Sustentable 8, pp. $15-44$.

Puigverd, A. (2008), “El miedo, coste del progreso”, La Vanguardia, 22IX.

Reigota, M. (2000), “La transversalidad en Brasil: Una banalización neoconservadora de una propuesta pedagógica radial”, Tópicos en Educación Ambiental, volumen 2 número 6, pp. 19 - 26.

Rifkin, J. (2000), La era del acceso: la revolución de la nueva economía, Barcelona, Paidós.

Ídem (2002), La economía del hidrógeno, Barcelona, Paidós.

Rodríguez, M.L. (2006), “La problemática del sujeto histórico”, Paradigmas [http://paradygmes.unblog.fr/2006/07/24/la-problematica-delsujeto-historico/]

Ruiz, C. y Conde, E. (2002), "El uso del medio ambiente en la publicidad”, en Medio Ambiente y Comportamiento Humano 3(1), 89-101.

Sorrel, S. (2007), The rebound effect: an assessment of the evidence from economy-wide energy savings from improved energy efficiency [http:// www.ukerc.ac.uk/Dowloads/PDF/07/0710ReboundEffect/071Rebound EffectReport.pdf]. 